\title{
Train Collision Avoidance \& Crack Detection Using GPS
}

\author{
Manoj Sai, E. Bijolin Edwin, Mani Arun, Santhosh Paul, Sudarshan
}

\begin{abstract}
In this day's people are using different transport systems from one place to another place. Among all the transportation people prefer public transport as their choice for safer journey. So the transportation department takes several checks to measure the safety of the people. The proposed system is for identify and avoid the cracks in railway tracks and collision in-order to prevent the accidents. In this paper to use crack detection and ZIGBEE sensor this will be placed in the train engine. By this if any train comes in the same track or if some crack is detected on the crack the rain starts to slow down and stop at respective point automatically and the place where the crack would be given to control room. In the train collision avoidance system if both the trains are in the same track the both ZIGBEE sensor senses the same signal from opposite train then it automatically applies break and stop the train at certain distance. The proposed system introduces trans receiver based technology, to prevent the trains accident. The ZIGBEE device is installed at each front-end of the locomotive. The main idea of the work is to avoid the train accidents and reduce the manual power.
\end{abstract}

Keywords-GSM modem, GPS, Train positioning, Microcontroller, IR crack sensors, ZIGBEE.

\section{INTRODUCTION}

In the current situation cracks and other problems with the track generally go unnoticed due to the improper maintenance and irregular manual track line that is being carried out by the railway employees. There are some limitations in the present existing system, If any track is damaged, the information will reach the railway authority people, they notifies and informs to the higher authority people. It will take more time to informing those information. In the literature survey the technologies which are commonly employed for rail crack detection in foreign countries are expensive, which are ineligible for implementation in the current Indian scenario. So our proposed system uses moderate cost which reduces the budget to implement the system with low cost. It is not only concentrated on finding the crack of track but also helps to find out the derailment and the exact place where it is. The

solutions which are offered by the different technical companies in the crack detection of track involve periodic maintenance coupled with occasional monitoring usually twice a week. But there are several advantages in facilitating monitoring of rail track by robotics possession on a daily basis during night. The easy availability of the components and the simplicity of the idea makes the implementation on the large scale with very little investment. The robustness of the operation will be ensured by the simplicity of the work and also the design has been carefully modified to permit rugged operation. Another disadvantage that can be attributed to the conventional commercially available testing equipment is that they are heavy which poses a particular limitation. So the proposed system will overcome most of the limitation in the existing system of crack detection and collision avoidance.

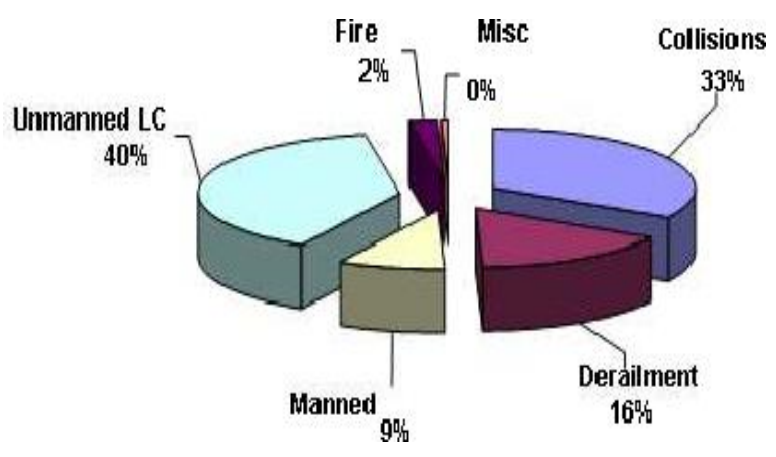

Fig 1.1 Causalities in Train Accidents during 1995-96 to 2016-17

\section{ARCHITECTURE DIAGRAM}

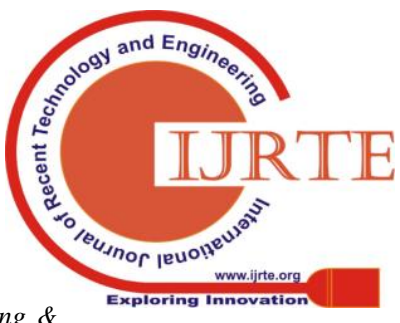
Sciences Publication 


\section{Train Collision Avoidance \& Crack Detection Using GPS}

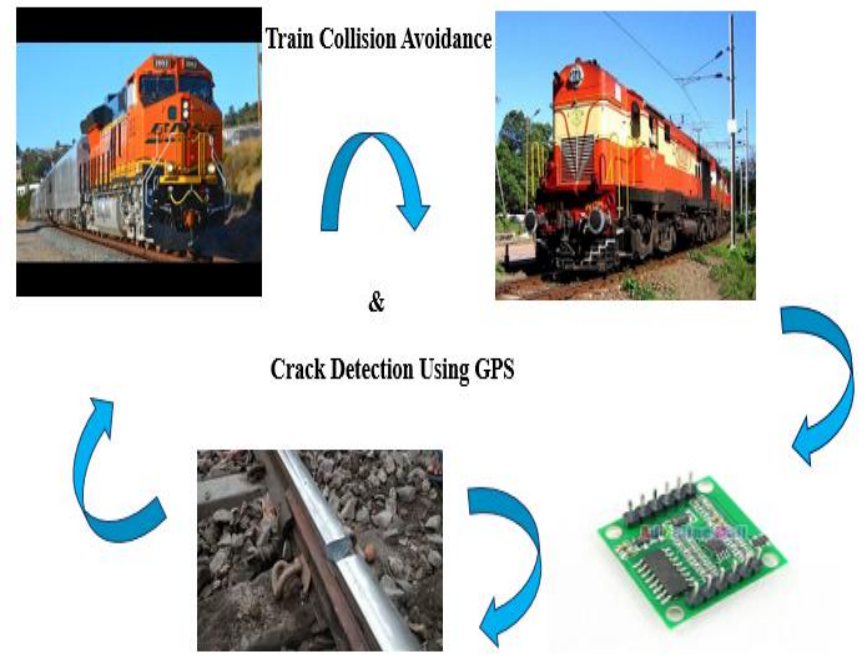

Fig 1.2 Train Collision Avoidance \& Crack Detection Using GPS

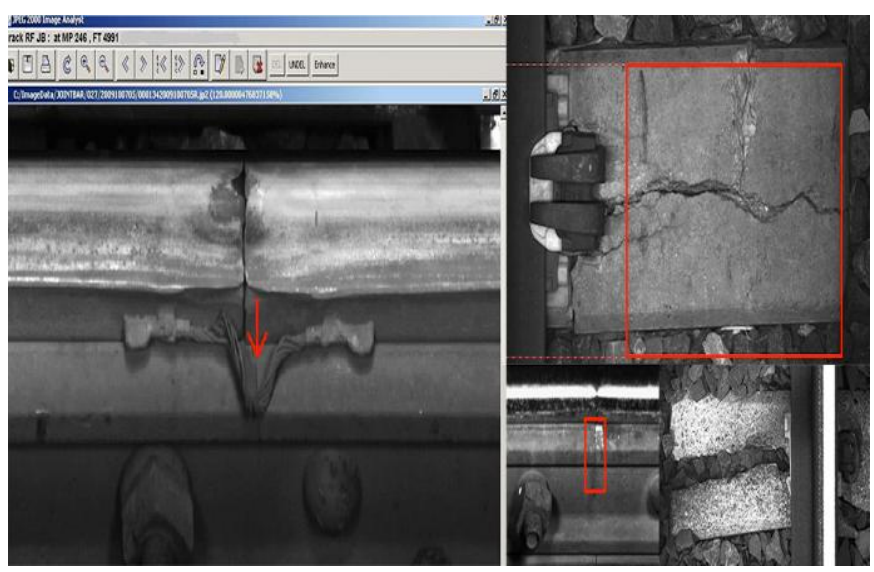

Fig 1.3 Crack detection of Railway Track

\section{FLOW CHART}

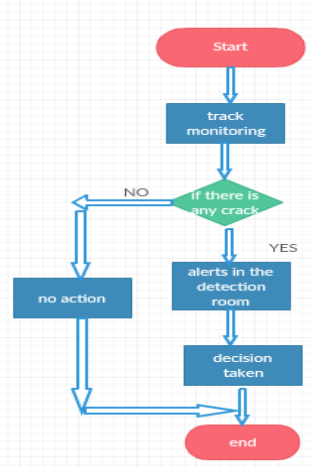

The flow chart diagram that we have drawn from the UML software. Where it describes about the total process. Where it start from the initializing LCD, GPS, GSM Modules, Ports, and then checking the distance it moves to the decision box. If train is in the same track it shows the speed of the train. If there is any track then it alerts in the detection room. There is no crack it won't take any action. Any crack is there it alerts and send it to the detection room and the decision can be taken to avoid the collision of the train.
It checks for the cracks that are present on the Railway track and when the train comes it detects the through the IR sensor and also it avoids the train collision through the GPS and GSM modules first it checks the distance. If the distance is less than the train range it search the GPS and send the GPS location through the GSM module.

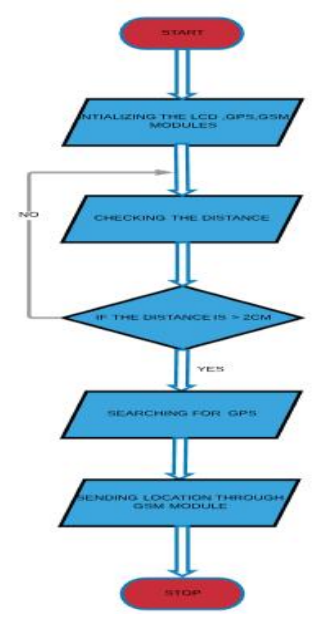

\section{BLOCK DIAGRAM :}

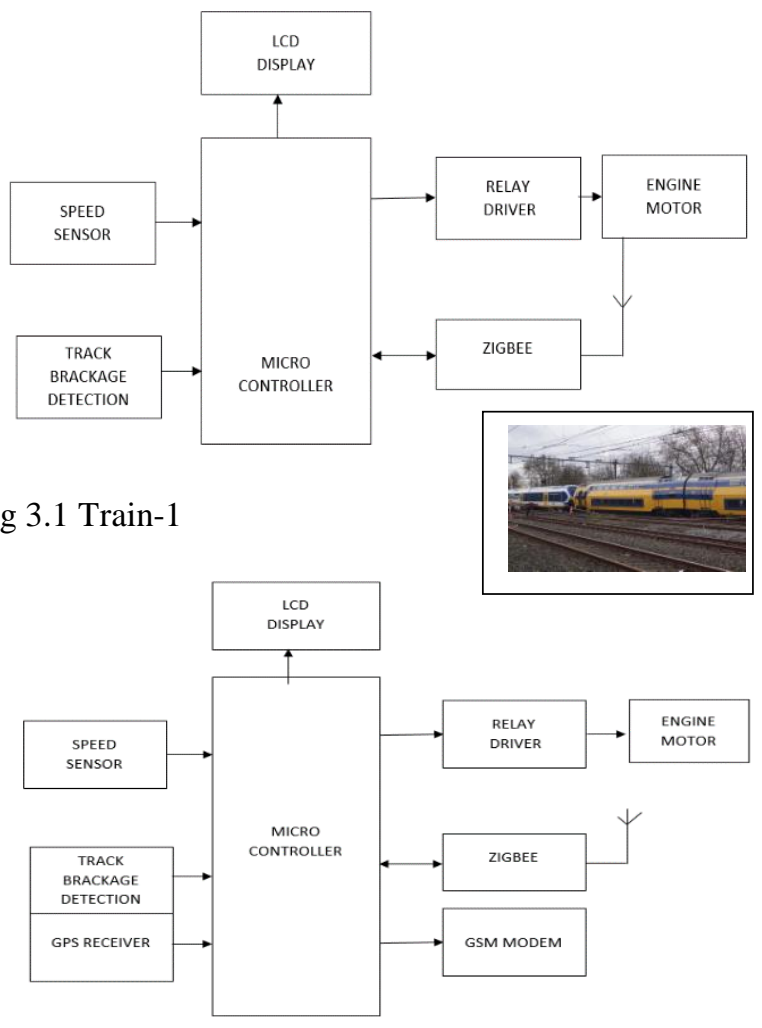

Fig 3.2 Train-2 


\section{A.MICROCONTROLLER :}

The proposed system uses the microcontroller from PIC series. The first RIC based microcontroller fabricated in CMOS (complimentary metal oxide semiconductor) is PIC microcontroller. Which uses separate bus for instruction and data allowing simultaneous access of program and data memory. Low power consumption resulting in a very small chip size with a small pin count is the main advantage of the CMOS and RISC combination. The immunity to noise than other fabrication technologies is the main advantage of the CMOS.

Different kinds of memories are offered by various microcontrollers. EEPROM, EPROM, FLASH are the most recently developed memories which offers FLASH. FLASH technology has been used in the PIC16F877 so the data is retained even when the power is switched off. Other feature of PIC16F877 are easy programming and erasing.

\section{PIN DIAGRAM :}

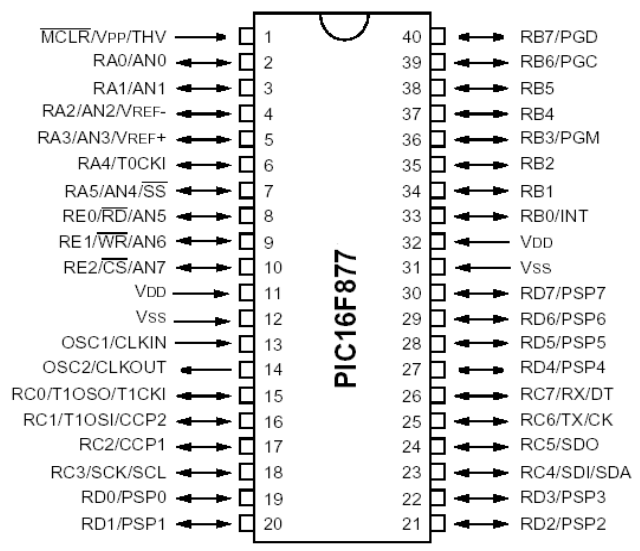

Fig 3.3 Pin Diagram of PIC 16F877

\section{B. LCD DISPLAY :}

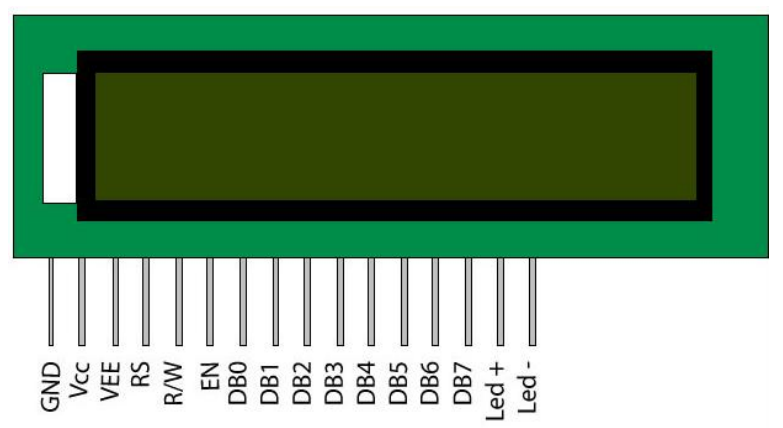

Fig 3.4 16x2 LCD Display

LCD (Liquid Crystal Display) screen is an electronic display module with a wide range of applications. Very commonly used 16x2 LCD display is used in this proposed system. The $16 \times 2$ LCD screens are preferred over seven segments and other multi-segment LEDs. The reasons behind using this LCDs are they are economical, easily programmable, have no limitation of displaying special and even custom characters, animations and so on. A 16x2 LCD can display 16 characters per line and there are 2 such lines. In this LCD each character is displayed in 5x7 pixel matrix. Command and data are the two registers namely. The command instructions which are given to LCD will be stored in command register. Pre-defined tasks like initializing, it clearing it's screen, setting the cursor position, controlling display will be done by the command instruction.

\section{GSM:}

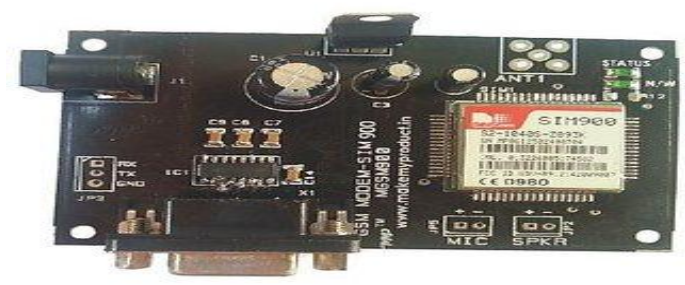

Fig 3.5 Global System Mobile Communication

Global system for mobile communication

If anyone misses their output condition to fail then there is defect on that side. It will be informed by GSM with GPS location in particular location.In this project GPS sensor is attached in the two trains to monitor the current position of the train

\section{WORKING METHODOLOGY}

\section{A. PHOTOSHOT:}

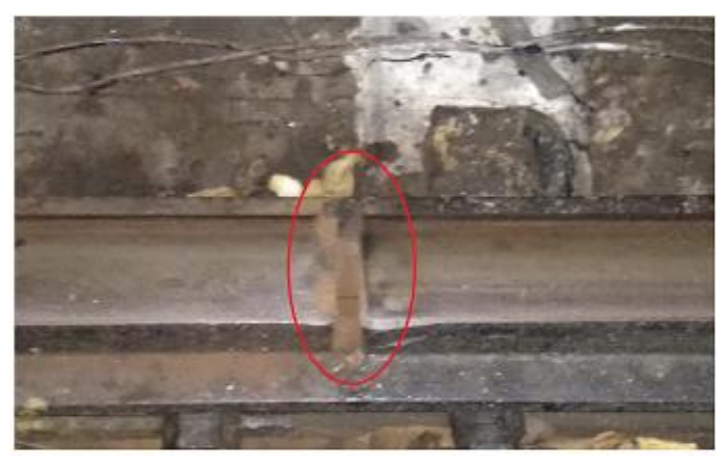

Fig 4.1 Crack On Railway Track

This proposal pertains to a process for monitoring the condition of rail on train tracks. IR sensors are fixed in the wheels of the train is used to find out the crack on the rail. Each sensor will produce the signal related position with the rail. If the track is said to be normal on its position when both the sensor gives the constant sensed output. If anyone misses their output condition to fail then there is defect on that side. It will be informed by GSM with GPS location in particular location. In this proposed system GPS sensor is attached in the two trains to monitor the current position of the train. The GPS sensor consists of GPS antenna and GPS receiver. GPS uses satellite ranging to triangulate vehicle position. In other words, the GPS unit simply measures the travel time of the signals transmitted from the satellites, then multiplies them by the speed of light to determine exactly how far the unit is from every satellite its sampling. By locking onto the signals from a minimum of three different satellites, a GPS receiver can calculate a 2D (two-dimensional) positional fix, consisting of your vehicle latitude and longitude. At the same time speed sensor is used to measure the speed of both train and it will transmit wirelessly use ZIGBEE. If both train are in same track both train receive opposite train speed and train number using ZIGBEE Trans 
receiver. So it is very helpful to train driver know if any train in same track then stop the train to avoid the accident.

\section{B. GRAPH :}

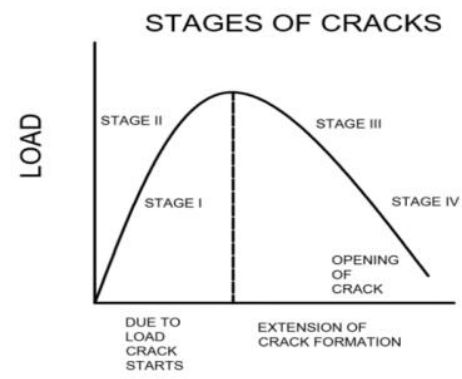

Fig 4.2 Stages of Cracks

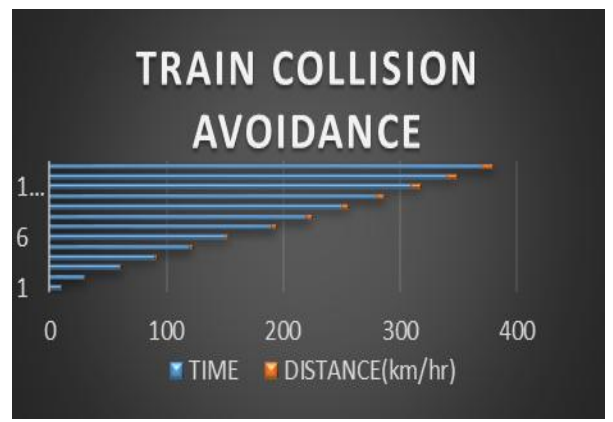

Fig 4.3 Train Collision Avoidance

a. ser_out(v1\%1000/100+0x30);

b. ser_out(v1\%100/10+0x30);

c. ser_out(v1\%10+0x30);

To find the speed of the train:

$$
\begin{aligned}
& \mathrm{d}[2]=\mathrm{d}[2]-0 \times 30 ; \\
& \mathrm{d}[3]=\mathrm{d}[3]-0 \times 30 ; \\
& \mathrm{d}[4]=\mathrm{d}[4]-0 \times 30 ; \\
& \mathrm{d}[5]=\mathrm{d}[5]-0 \times 30 ;
\end{aligned}
$$
speed $=\mathrm{d}[2] * 1000+\mathrm{d}[3] * 100+\mathrm{d}[4] * 10+\mathrm{d}[5]$;

[1]. d2, d3, d4, d5 are the variables.

\section{PSEUDO CODE}

$$
\begin{aligned}
& \mathrm{d}[2]=\mathrm{d}[2]-0 \times 30 \\
& \mathrm{~d}[3]=\mathrm{d}[3]-0 \times 30 \\
& \mathrm{~d}[4]=\mathrm{d}[4]-0 \times 30 \\
& \mathrm{~d}[5]=\mathrm{d}[5]-0 \times 30 \\
& \text { speed=d[2]*1000+d[3]*100+d[4]*10+d[5]; } \\
& \text { command(0xc6); } \\
& \text { hex_dec(speed); }
\end{aligned}
$$
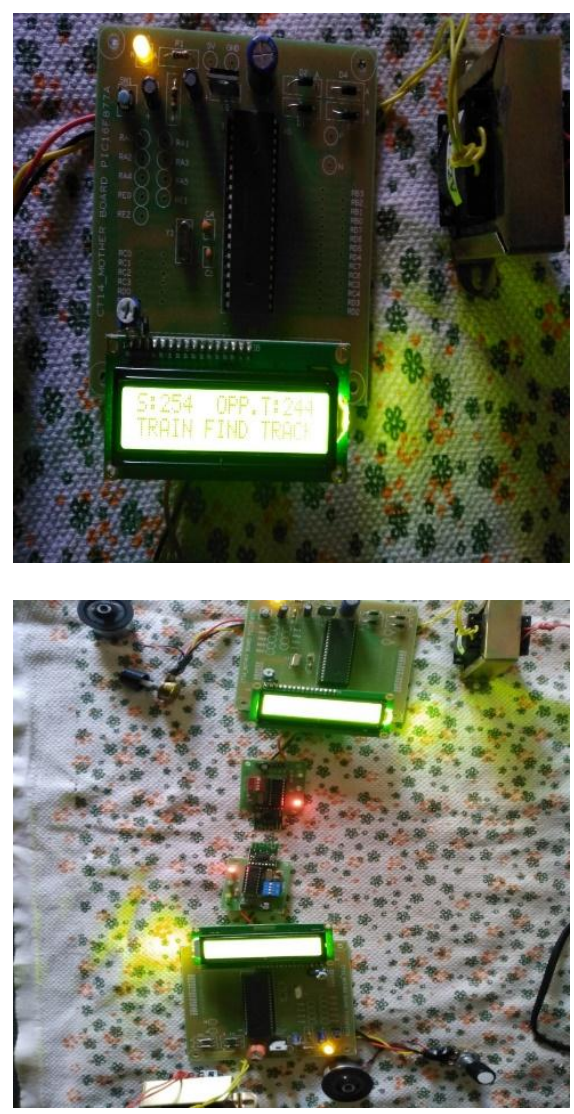

Fig 6.1 Implementation of Train Collision Avoidance

\section{CONCLUSION \& FUTURE WORKS}

The propose collision avoidance systems are especially useful in bad weather conditions. A design for automatically averting train collisions and accidents occurring due to crack formation have been designed, simulated and tested. It uses the advanced features of PIC16F877 micro controller with ZIGBEE communication technique, proves to be effective in achieving the objects. It is applicable for many aspect of the railways for uninterruptible service. The silent features like saving human life, protection against accidents and the communicable electronic systems are the main advantage of this system. From the above discussion and information of this system we, up to now surely comes to know that it is highly reliable effective and economical at dense traffic area, sub urban area and the route where frequency of trains is more. As it saves some auxiliary structure as well as the expenditure on attendant it is more economical at above mentioned places than traditional railway crossing gate system. We know that though it is very beneficial but it is also impossible to install such system at each and every place, but it gives certainly a considerable benefit to us, thereby to our nation. In future, we will also use the CCTV systems with IP based camera for monitoring the visual videos captured from the track. It will also increase the security for the both rails and passengers. 


\section{REFERENCES}

[1] Aamir Shaikh,Siraj Pathan " Research on Wireless Sensor Network Technology " in International Journal of Information and Education Technology, October 2012.

[2] Chengbo YU, Yanfei LIU, Cheng WANG "Research on ZigBee Wireless Sensors Network Based on ModBus Protocol " Published Online April 2009 in SciRes.

[3] Dr.S.S.Riaz Ahamed "THE ROLE OF ZIGBEE TECHNOLOGY IN FUTURE DATA COMMUNICATION SYSTEM " in Journal of Theoretical and Applied Information Technology 2009.

[4] Arun.P, Saritha.S, K.M.Martin, Madhukumar.S "Simulation of zigbee based TACS for collision detection and avoidance for railway traffic., "in International conference on advanced computing \& communication technologies for high performance application, paper ID 51,June 2012 .

[5] "Communication Systems" by Simon Hawkins.

[6] Jennic, JN-AN-1059 Deployment guidelines for IEEE 802.15.4/ZigBee wireless networks, 37-38, 2007

[7] D.Roychoudary and Sail Jain”L.I.C”, New Age International.

[8] Kenneth.J.Ayala"The 89C51 Microcontroller Architecture programming and Applications", Pen ram International.

[9] Ramesh.S, "Detection of Cracks and Railway Collision Avoidance System," International Journal of Electronic and Electrical Engineering, Volume 4, Number 3, pp. 321-327, 2011.

[10] Richard j.Greene ,john R.Yates and Eann A.Patterson,"Crack detection in rail using infrared methods",Opt.Eng.46,051013,May 2007.

[11] Sonia Shah, Ravi Mishra "Train Positioning and Crack Detecting System" in International Journal of Scientific Research in Science, Engineering and Technology March-April 2016.

[12] Parneet Dhillon ,Dr. Harsh Sadawarti "A Review Paper on Zigbee Standard" in International Journal of Engineering Research \& Technology , April 2014.

[13] Christeena Joseph ,A.D.Ayyappan , A.R.Aswini, B.Dhivya Bharathy "GPS/GSM Based Bus Tracking System " in International Journal of Scientific \& Engineering Research,December-2013.

\section{AUTHORS PROFILE}

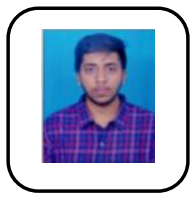

Manoj Sai, currently pursuing B.Tech in Computer Science and Engineering from Karunya Institute of Technology and Sciences, Coimbatore, Tamil Nadu, India. Her area of interests includes Web Desigining and DBMS.

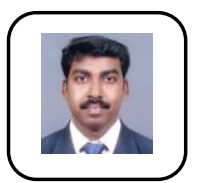

E.Bijolin Edwin is an Assistant Professor in the Department of Computer Science and Engineering, Karunya Institute of Technology and Sciences, Coimbatore, India. He received his Master of Engineering and Ph.D from Anna University, Chennai, India. His research interests include Cloud Computing, Machine Learning. He is an Life time member of Computer Society of India

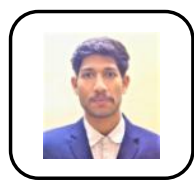

Mani Arun Kumar Reddy, currently pursuing B.Tech in Computer Science and Engineering from Karunya Institute of Technology and Sciences, Coimbatore, Tamil Nadu, India. Her area of interests includes Analysis of Algorithm and Networking.

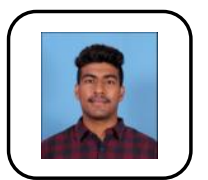

Sudarshan, currently pursuing B.Tech in Computer Science and Engineering from Karunya Institute of Technology and Sciences, Coimbatore, Tamil Nadu, India. Her area of interests includes Internet of things and Artificial Intelligence for Games.

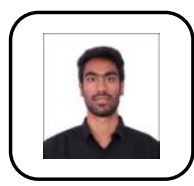

Santhosh Paul, currently pursuing B.Tech in Computer Science and Engineering from Karunya Institute of Technology and Sciences, Coimbatore, Tamil Nadu, India. Her area of interests includes Data structures and Game development. 